\title{
High-risk human papillomavirus infection is associated with premature rupture of membranes
}

\author{
GeumJoon Cho ${ }^{1 \dagger}$, Kyung-Jin Min ${ }^{2 \dagger}$, Hye-Ri Hong ${ }^{2}$, SuhngWook Kim ${ }^{3}$, Jin-Hwa Hong ${ }^{1}$, Jae-Kwan Lee ${ }^{1}$,
} Min-Jeong $\mathrm{Oh}^{1^{*}}$ and HaiJoong Kim ${ }^{1}$

\begin{abstract}
Background: Human papillomavirus (HPV) is known to be more prevalent in spontaneous abortions than in elective terminations of pregnancy. More recently, placental infection with HPV was shown to be associated with spontaneous preterm delivery. However, no study has evaluated the prevalence of HPV infection in pregnant Korean females and its association with adverse pregnancy outcomes.

Methods: We conducted a cross-sectional study of 311 females who gave birth at Korea University Medical Center. Our sample included 45 preterm deliveries, 50 cases of premature rupture of the membranes (PROM), 21 preeclampsia cases, and 8 gestational diabetes mellitus (GDM) patients. We used the Hybrid Capture II system to detect high-risk (HR)-HPV infection at six weeks postpartum.

Results: The prevalence of HR-HPV infection was $14.1 \%$. Women with HR-HPV infection had a higher incidence of PROM than those without HR-HPV. HR-HPV infection was associated with an increased risk of PROM (OR, 2.380; 95\% $\mathrm{Cl}, 1.103-5.134)$. The prevalence of preterm delivery, preeclampsia, or GDM was not different between the two groups.

Conclusions: We observed a high prevalence of HR-HPV infection in pregnant women. Moreover, HR-HPV infection was associated with a risk of PROM at term. Further studies are needed to evaluate mechanisms by which HR-HPV infection induces PROM.
\end{abstract}

Keywords: Human papillomavirus, Pregnancy, Complication

\section{Background}

Cervical cancer is the fifth most common cancer in females, and it accounts for $9.7 \%$ of malignancies in women. If cervical carcinoma in situ is included, then this malignancy is the second most common female cancer in Korea [1].

Human papillomavirus (HPV) is a small, double-stranded DNA virus. High-risk (HR)-HPV is considered to be the main cause of cervical cancer. Pregnancy is known to be an independent risk factor for HR-HPV infection [2]. Although little information is available regarding the association between HPV infection and pregnancy outcome, HPV has been reported to be more prevalent in spontaneous abortions than in elective terminations of pregnancy [3]. More recently, placental infection with HPV was shown

\footnotetext{
* Correspondence: mjohmd@korea.ac.kr

${ }^{\dagger}$ Equal contributors

'Department of Obstetrics and Gynecology, College of Medicine, Korea University, Seoul, Korea

Full list of author information is available at the end of the article
}

to be associated with spontaneous preterm delivery [4]. However, no study has evaluated the effects of HR-HPV infection in pregnant Korean females. The aim of this study was to evaluate the prevalence of HR-HPV infection in pregnant Korean women and the association between HRHPV infection and adverse pregnancy outcomes.

\section{Methods}

We conducted a cross-sectional study of 311 women who gave a birth at Korea University Medical Center (KUMC) from February 2010 to January 2011 and came to KUMC for follow-up at 6 weeks postpartum. Our analysis included 45 preterm deliveries, 50 women with premature rupture of the membranes (PROM), 21 cases of preeclampsia, and 8 gestational diabetes mellitus (GDM) patients. All women provided written informed consent, prior to participation in the study, which was approved by the ethical committee (Korea University Guro Hospital IRB) at our institution.

\section{Biomed Central}


We used the Hybrid Capture II system (Digene Diagnostics Inc., Gaithersburg, MD, USA) for detection of HR-HPV infection (HPVs 16, 18, 31, 33, 35, 39, 45, 51, $52,56,58,59$, and 68 ) at six weeks postpartum. The samples were obtained in the cervix. We collected the basic characteristics, such as age, parity, number of abortions, body weight and height of pregnant women, gestational age at delivery, Apgar score and birth weight of each neonate, smoking status, history of PROM, history of preterm birth, and delivery mode by medical chart review. Body mass index (BMI) is defined as the individual's body weight (kilogram) divided by the square of their height (meter).

Preterm delivery was defined as delivery before the 37th week of gestation. PROM is the rupture of membranes at any given time during pregnancy prior to the onset of labor. Patients were diagnosed with preeclampsia if they had a maternal blood pressure of $\geq 140 / 90 \mathrm{mmHg}$ recorded on two occasions at least six hours apart after 20 weeks of gestation without a previous history of hypertension and also if they had concomitant proteinuria $(\geq 300$ $\mathrm{mg} / 24$ hours urine or $\geq 1+$ in dipstick test). GDM was diagnosed according to the American Diabetes Association (ADA) criteria [5].

Data are reported as mean \pm standard deviation for continuous variables and as a percentage for categorical variables. Clinical characteristics in participants both with and without HR-HPV infection were compared using Student's t-test and the Chi-square test or Fisher's exact tests, when the variables were continuous and categorical, respectively. We conducted a multivariate logistic regression analysis to investigate the relationship between adverse pregnancy outcomes and HR-HPV infection. All reported $p$-Values were two-tailed. Statistical analyses were performed using the Statistical Package for the Social Sciences (SPSS) software, version 12.0 (SPSS Inc., Chicago, IL, USA).

\section{Results}

HR-HPV infection was present in $14.1 \%$ of the study participants. The characteristics of these participants are presented in Table 1 according to either the presence or absence of HR-HPV infection. No significant differences in age, BMI, parity, and number of abortion were observed between women with HR-HPV infection and those without HR-HPV infection. There were no differences in gestational age at delivery or in birth weight between the two groups. Distributions of delivery mode also did not vary substantially between the two groups.

Table 2 shows the prevalence of adverse pregnancy outcomes based on the presence or absence of HR-HPV infection. PROM was more common in patients with HR-HPV infection than in women without HR-HPV. However, the prevalence of preterm delivery, preeclampsia, and GDM was similar between the two groups.

Figure 1 shows the prevalence of HR-HPV infection according to age group. HR-HPV infection was more common in women below the age of 25 .

A multivariate logistic regression analysis was used to evaluate the relationship of PROM with HR-HPV infection (Table 3). After controlling for age, parity, number of abortions, BMI, gestational age at delivery, history of preterm birth, and history of PROM, we found that women with HR-HPV infection had an increased risk of PROM (odds ratio, 2.318; 95\% confidence interval, 1.079-4.980), when compared with those without HRHPV infection.

Table 1 Characteristics of the study participants according to the presence or absence of HR-HPV infection

\begin{tabular}{|c|c|c|c|}
\hline & \multicolumn{2}{|c|}{ HR-HPV infection test } & \multirow[t]{2}{*}{$p$-Value } \\
\hline & Negative $(N=267)$ & Positive $(N=44)$ & \\
\hline Age (years) & $31.23 \pm 4.02$ & $30.43 \pm 4.82$ & 0.304 \\
\hline Parity & $0.49 \pm 0.70$ & $0.36 \pm 0.61$ & 0.217 \\
\hline Number of abortions & $0.73 \pm 1.06$ & $0.64 \pm 0.99$ & 0.582 \\
\hline BMI $\left(\mathrm{kg} / \mathrm{m}^{2}\right)$ & $26.45 \pm 3.46$ & $26.43 \pm 3.59$ & 0.963 \\
\hline 1-min Apgar score & $8.43 \pm 1.79$ & $8.74 \pm 1.43$ & 0.204 \\
\hline 5-min Apgar score & $9.49 \pm 1.11$ & $9.63 \pm 0.82$ & 0.331 \\
\hline Gestational age at delivery (weeks) & $37.27 \pm 4.03$ & $38.08 \pm 2.72$ & 0.203 \\
\hline Birth weight $(\mathrm{kg})$ & $2.87 \pm 0.82$ & $3.01 \pm 0.54$ & 0.270 \\
\hline Delivery mode (\%) & & & 0.728 \\
\hline Vaginal delivery & 50.6 & 47.7 & \\
\hline Cesarean section & 49.4 & 52.3 & \\
\hline Preterm birth history (\%) & 4.1 & 4.5 & 1.000 \\
\hline PROM history (\%) & 3.4 & 4.5 & 0.659 \\
\hline
\end{tabular}

HR: High risk, HPV: Human papillomavirus, BMI: Body mass index, PROM: Premature rupture of the membranes. 
Table 2 Prevalence of adverse pregnancy outcomes according to the presence or absence of HR-HPV infection

\begin{tabular}{lccc}
\hline $\begin{array}{l}\text { Maternal } \\
\text { complications (\%) }\end{array}$ & \multicolumn{2}{c}{ HR-HPV infection test } & $\boldsymbol{p}$-Value \\
\cline { 2 - 3 } & $\begin{array}{l}\text { Negative } \\
(\boldsymbol{N}=\mathbf{2 6 7})\end{array}$ & $\begin{array}{c}\text { Positive } \\
(\boldsymbol{N}=\mathbf{4 4 )}\end{array}$ & \\
\hline Preterm delivery & 13.9 & 15.9 & 0.718 \\
\hline PROM & 14.2 & 27.3 & 0.029 \\
\hline Preeclampsia & 7.9 & 0 & 0.054 \\
\hline GDM & 2.2 & 4.5 & 0.316
\end{tabular}

HR: High risk, HPV: Human papillomavirus, PROM: Premature rupture of the membranes, GDM: Gestational diabetes mellitus.

\section{Discussion}

To our knowledge, our study is the first to report on an association between HR-HPV infection and PROM. Women who experienced PROM were more likely to experience HR-HPV infection than those without PROM.

Although it is widely accepted that PROM is multifactorial, infection has been cited as a major cause of membrane damage [6]. One possible mechanism for membrane damage resulting from infection is that several organisms secrete cytokines, such as metalloproteases (MMP), that degrade collagen and weaken the fetal membranes, which can lead to rupture [7]. It has been reported that MMP-2 in particular degrade the extracellular matrix of the fetal membrane, resulting in PROM [8]. MMP-2 is also an important factor in the invasion of cervical cancer through degradation of the extracellular matrix [9]. Interestingly, the presence of HPV in human invasive cervical carcinoma cell lines is related to an increase of MMP-2 expression; this association suggests that HPV could play a role in the regulation of MMP [10]. The fetal membranes overlie the cervix, where HR-HPV is easy to contract and which is the most likely site for membrane rupture [11]; this close proximity may allow HR-HPV infection to contribute to PROM. Additionally, several studies have found

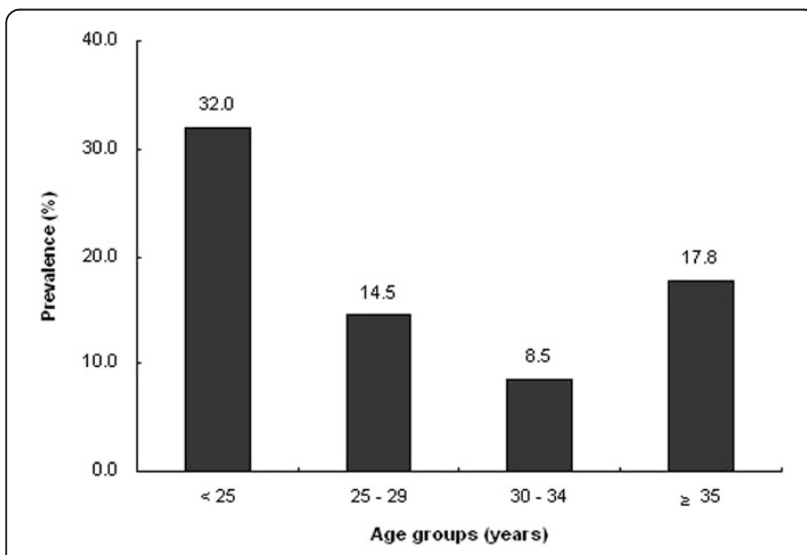

Figure 1 Prevalence of high risk-human papillomavirus infection according to age group.
Table 3 Odds ratios (OR) of HR-HPV infection and demographic variables for PROM

\begin{tabular}{lcc}
\hline & $\begin{array}{c}\text { Unadjusted OR } \\
\mathbf{( 9 5 \% ~ C l )}\end{array}$ & $\begin{array}{c}\text { Adjusted OR } \\
\mathbf{( 9 5 \% ~ C l )}\end{array}$ \\
\hline HR-HPV infection & $2.260(1.071-4.770)$ & $2.318(1.079-4.980)$ \\
\hline Age & $0.980(0.910-1.054)$ & $0.986(0.908-1.072)$ \\
\hline Parity & $0.918(0.583-1.446)$ & $0.737(0.416-1.307)$ \\
\hline Number of abortions & $1.113(0.850-1.457)$ & $1.168(0.872-1.538)$ \\
\hline BMl & $1.029(0.944-1.121)$ & $1.047(0.956-1.146)$ \\
\hline Gestational age at delivery & $0.960(0.894-1.030)$ & $0.941(0.870-1.017)$ \\
\hline History of preterm birth & $2.435(0.720-8.239)$ & $1.466(0.278-7.728)$ \\
\hline History of PROM & $3.155(0.888-11.213)$ & $2.977(0.555-15.965)$ \\
\hline
\end{tabular}

PROM: Premature rupture of the membranes, OR: Odds ratio, Cl: Confidence interval, HR-HPV: High risk human papillomavirus, BMI: Body mass index.

${ }^{\text {a }}$ The model is adjusted for variables in the table.

an increased rate of HPV infection in women with other genital infections [12,13], which have been implicated as a major etiological factor in the pathogenesis of PROM [14]. Therefore, HPV infection could simply exist harmlessly along with other infections that are the true cause of PROM. Further studies are needed to determine the relationship between HR-HPV infection and PROM.

In this study, the prevalence of HR-HPV infection was $14.1 \%$. Inconsistencies exist in the literature on the incidence of HR-HPV infection in pregnant women. The reported prevalence of HR-HPV infection in pregnancy varies between $5 \%$ and $40 \%[15,16]$. This wide range is related to several factors, including ethnicity, choice of detection methods, HR-HPV type, study design, and risk-factor profiles, such as maternal age, gestational age, and a history of cesarean section. In our study, women aged $\leq 25$ years were more likely to have HR-HPV infection than women $>25$ years. However, there was no difference of age between women with HR-HPV infection and those without HR-HPV infection in our study. This result may be explained partly by the low recruitment of women aged $\leq 25$ years ( $8 \%$ of all women) in our study. Previous results of studies associating HPV infection with gestational age, another factor, have been mixed $[17,18]$. In our study, gestational age at delivery was not different between the two groups, although it was measured postpartum. These results suggest a balance between the acquisition and clearance of HR-HPV infection during and after pregnancy [18].

Our findings have several limitations. First, PROM was not classified according to the gestational age. PROM at term does not have the same clinical impact as PPROM. But, because PROM at term also has several complications, such as increased maternal infections and neonatal intensive care unit admissions, we think that our study has enough meaning [19]. In addition, in our study, 43 pregnant women delivered at less than 34 weeks. We thought that there is not a statistically significant because 
the number of cases is small. But, these values are similar to our results, $14.3 \%$ in HR-HPV-negative and $27.3 \%$ in HR-HPV positive. We were trying to compensate for the effect of gestational age through multivariate logistic regression analysis. After adjusting for gestational age at delivery, HR-HPV infection was showed a statistically significant association with PROM. So, the large scaled study should be needed on the association of HR-HPV infection and PROM according to gestational age. Second, our study was cross-sectional, which limits our ability to determine the cause and effect of HR-HPV infection on adverse pregnancy outcomes. Third, we lacked information regarding sexual behavior (i.e., number of sexual partners, use of condoms, and other active sexually transmitted infections) and previous medical histories (i.e., immunocompromise, and HIV), which can act as or increase the risk factors for PPROM, spontaneous preterm delivery, and HR-HPV infection during pregnancy. However, these limitations did not prevent our study from finding an association between HR-HPV infection and adverse pregnancy outcomes.

\section{Conclusion}

In this study, we observed a high prevalence of HR-HPV infection in pregnant women. HR-HPV infection was also associated with a higher risk of PROM at term. Further studies are needed to evaluate the mechanism by which HR-HPV infection induces PROM.

\section{Competing interests}

The authors declare that they have no competing interests.

\section{Authors' contributions}

GJC, KJM, HRH, and MJO conceived of the study, and participated in its design and coordination. JHH, JKL, SWK, and HJK performed the statistical analysis. GJC and KJM participated in the sequence alignment and drafted the manuscript. All authors read and approved the final manuscript.

\section{Author details}

${ }^{1}$ Department of Obstetrics and Gynecology, College of Medicine, Korea University, Seoul, Korea. ${ }^{2}$ Department of Obstetrics and Gynecology, Inha University Hospital, Incheon, Korea. ${ }^{3}$ Department of Biomedical Science,

College of Health Sciences, Korea University, Seoul, Korea.

Received: 3 January 2013 Accepted: 30 August 2013

Published: 6 September 2013

\section{References}

1. Ministry of Health and Welfare: 2002 Annual report of the Korea central cancer registry. Seoul: Ministry of Health and Welfare; 2003.

2. Fife KH, Katz BP, Roush J, Handy VD, Brown DR, Hansell R: Cancerassociated human papillomavirus types are selectively increased in the cervix of women in the first trimester of pregnancy. Am J Obstet Gynecol 1996, 174(5):1487-1493.

3. Hermonat PL, Han L, Wendel PJ, Quirk JG, Stern S, Lowery CL, Rechtin TM: Human papillomavirus is more prevalent in first trimester spontaneously aborted products of conception compared to elective specimens. Virus Genes 1997, 14(1):13-17.

4. Gomez LM, Ma Y, Ho C, McGrath CM, Nelson DB, Parry S: Placental infection with human papillomavirus is associated with spontaneous preterm delivery. Hum Reprod 2008, 23(3):709-715.
5. American Diabetes Association: Diagnosis and classification of diabetes mellitus. Diabetes Care 2006, 29(Suppl 1):S43-S48.

6. Riedewald S, Kreutzmann IM, Heinze T, Saling E: Vaginal and cervical pH in normal pregnancy and pregnancy complicated by preterm labor. J Perinat Med 1990, 18(3):181-186.

7. Goldenberg RL, Hauth JC, Andrews WW: Intrauterine infection and preterm delivery. N Engl J Med 2000, 342(20):1500-1507.

8. Ota A, Yonemoto H, Someya A, Itoh S, Kinoshita K, Nagaoka I: Changes in matrix metalloproteinase 2 activities in amniochorions during premature rupture of membranes. J Soc Gynecol Investig 2006, 13(8):592-597.

9. Kato Y, Yamashita T, Ishikawa M: Relationship between expression of matrix metalloproteinase- 2 and matrix metalloproteinase- 9 and invasion ability of cervical cancer cells. Oncol Rep 2002, 9(3):565-569.

10. da Silva Cardeal LB, Brohem CA, Correa TC, Winnischofer SM, Nakano F, Boccardo E, Villa LL, Sogayar MC, Maria-Engler SS: Higher expression and activity of metalloproteinases in human cervical carcinoma cell lines is associated with HPV presence. Biochem Cell Biol 2006, 84(5):713-719.

11. McLaren J, Malak TM, Bell SC: Structural characteristics of term human fetal membranes prior to labour: identification of an area of altered morphology overlying the cervix. Hum Reprod 1999, 14(1):237-241.

12. Watts DH, Fazzari M, Minkoff H, Hillier SL, Sha B, Glesby M, Levine AM, Burk $R$, Palefsky JM, Moxley M, et al: Effects of bacterial vaginosis and other genital infections on the natural history of human papillomavirus infection in HIV-1-infected and high-risk HIV-1-uninfected women. $J$ Infect Dis 2005, 191(7):1129-1139.

13. Lukic A, Canzio C, Patella A, Giovagnoli M, Cipriani P, Frega A, Moscarini M: Determination of cervicovaginal microorganisms in women with abnormal cervical cytology: the role of Ureaplasma urealyticum. Anticancer Res 2006, 26(6C):4843-4849.

14. Goldenberg RL, Culhane JF: Infection as a cause of preterm birth. Clin Perinatol 2003, 30(4):677-700.

15. Tenti P, Zappatore R, Migliora P, Spinillo A, Maccarini U, De Benedittis M, Vesentini N, Marchitelli G, Silini E, Carnevali L: Latent human papillomavirus infection in pregnant women at term: a case-control study. J Infect Dis 1997, 176(1):277-280.

16. Hernández-Girón C, Smith JS, Lorincz A, Lazcano E, Hernández-Avila M, Salmerón J: High-risk human papillomavirus detection and related risk factors among pregnant and nonpregnant women in Mexico. Sex Transm Dis 2005, 32(10):613-618.

17. Morrison EA, Gammon MD, Goldberg GL, Vermund SH, Burk RD: Pregnancy and cervical infection with human papillomaviruses. Int I Gynaecol Obstet 1996, 54(2):125-130.

18. Banura C, Franceschi S, van Doorn $\sqcup$, Arslan A, Kleter B, Wabwire-Mangen F, Mbidde EK, Quint W, Weiderpass E: Prevalence, incidence and clearance of human papillomavirus infection among young primiparous pregnant women in Kampala. Uganda. Int J Cancer 2008, 123(9):2180-2187.

19. Dare MR, Middleton P, Crowther CA, Flenady VJ, Varatharaju B: Planned early birth versus expectant management (waiting) for prelabour rupture of membranes at term (37 weeks or more). Cochrane database of systematic reviews 2006, 1, CD005302.

doi:10.1186/1471-2393-13-173

Cite this article as: Cho et al.: High-risk human papillomavirus infection is associated with premature rupture of membranes. BMC Pregnancy and Childbirth 2013 13:173.

\section{Submit your next manuscript to BioMed Central and take full advantage of:}

- Convenient online submission

- Thorough peer review

- No space constraints or color figure charges

- Immediate publication on acceptance

- Inclusion in PubMed, CAS, Scopus and Google Scholar

- Research which is freely available for redistribution 